becoming hidebound with tradition. Initiative is of high importance, and the shortness of the timelag between publication of information and its being brought to the notice of the individual needing it is largely a matter of adequate library, technical and clerical staff.

Miss E. W. Parker, of the Mond Nickel Co. Ltd., stressed the value of external literature surveys conducted outside the library as a means of supplement. ing information received in the library. Much valuable advance information can be obtained by co-operation and by contact with technical and scientific personnel all over the world. As regards bibliographical work, Miss Parker suggested that it is important to produce bibliographies in advance of the demand, and stressed the importance of attention to detail in such matters as well as in dealing with inquiries. It is doubtful whether any inaccuracies in such work can be described as minor. Mr. E. J. Carter emphasised aspects of the information service maintained by the Royal Institute of British Architects, stressing particularly the importance of maintaining a full service of journals and books inside the library and the value of propaganda regarding the services offered. $\mathbf{M r}$ T. M. Herbert described the information service recently developed as part of the research organisation of the London Midland and Scottish Railway.

An animated discussion, opened by Mr. J. P. Lamb, chief librarian to the City of Sheffield, with a paper entitled "The Public Library as an Aid to Industry and Research" and by Mr. B. M. Headicar with a paper, "Research : Where the Library and Librarian come in", focused attention on the general neglect of the municipal library by industry. $\mathrm{Mr}$. Lamb referred to the possibilities of co-operation between the public libraries and special libraries in regard to co-ordination of purchases of books and the pooling of periodicals and storage space. In the course of discussion, $\mathrm{Mr}$. Lamb directed attention to the changed conditions under which the reference library now operates and the necessity for some elasticity in adapting its former rigid procedure regarding the loan and exchange of books. Where local conditions permit rapid and easy book exchange a very useful field of co-operation between industrial and municipal libraries exists and a promising tendency is that towards the development of a pool of technical and specialised works between the strictly reference library and the general library.

Prof. M. Greenwood delivered a delightful paper on the "History and Sources of Official Vital Statistics" in which a keen sense of humour enabled him to make an apparently uninteresting theme eloquent and to convey to others something of the fascination the subject has for the expert as well as of the difficulties and pitfalls which beset those attempting to compare vital statistics or to base conclusions on them.

One of the most important discussions, to which very little time was allotted, however, was that initiated by Mr. A. A. Eldridge's report on the A.S.L.I.B. inquiry into technical and scientific abstracting. This inquiry was conducted by a small committee of which Mr. A. A. Eldridge was chairman and was the direct outcome of the informal conference convened by Mr. H. T. Tizard last year at the Imperial College of Science and Technology. The report presented by Mr. A. A. Eldridge was purely preliminary and outlined the general trend of the replies received to the questionnnaire. Some fifty replies had been received covering nearly all the important abstracting agencies in Great Britain, including research associations and imperial bureaux, the Department of Scientific and Industrial Research, the Royal Photographic Society, the Textile Institute, British Medical Journal, Bureau of Chemical Abstracts, Institution of Civil Engineers and various industrial firms like the British Aluminium Co. Ltd., J. Lyons and Co. Ltd., Imperial Chemical Industries Ltd., Metropolitan-Vickers Electrical Co., Ltd.

The report directs attention to the opportunity for co-operation in the purchase or examination of journals of secondary interest and distinguishes between overlap in preparation and unavoidable overlap in publication. The replies received in answer to the questions regarding the qualifications for abstractors and their selection should provide the Association with a valuable analysis of experience as a basis for useful suggestions in response to definite requests for help. Divergent opinions were expressed as to the value of authors' summaries where provided, and opinion was expressed in the discussion on the report that abstracts must be written from the point of view of the user for whom they are intended. This is particularly true of the industrial abstracting services, but such services are frequently run deliberately to supplement and not to replace the work of agencies like the Bureau of Chemical Abstracts and the view that abstracts are best contributed by specialists in a particular field finds little support in industry. The discussion suggested that full time abstractors who are generally familiar with the subject and its principal complexities are regarded as most satisfactory for the special libraries or information bureaux. Attention was also directed to the desirability of uniform practice in regard to the abbreviations used for journal references, etc., and the transliteration of names in non-Latin scripts, as well as to the difficulties in the way of co-operation presented by the introduction of abbreviations into the text of abstracts.

At the annual meeting, discussion on the report and on what members want of A.S.L.I.B., initiated by Mr. H. Robinson of the Textile Institute indicated a very lively appreciation of the valuable work which the Association is carrying out and the wide and useful field of co-operation open to it. Sir Charles Sherrington was elected president of the Association in succession to Mr. H. T. Tizard.

\title{
A Census of Summer Thunderstorms
}

$\mathrm{T}$ HE first annual report of the Thunderstorm Census Organisation, Langley Terrace, Huddersfield, deals statistically with the records obtained, largely with the aid of private observers, during the six summer months April-September of 1931. It is an amateur enterprise conducted by Mr. S. Morris Bower as a sequel to a similar investigation carried on during a long period by Mr. C. J. P. Cave into the occurrence of thunderstorms in winter. The British Rainfall Organization, which is now part of the organisation of the Meteorological Office, Air Ministry, no doubt began in much the same way to supply information about one meteorological element with a greater degree of detail than could possibly be done without the aid of voluntary observers. The demand for such detailed information about

No. 3285, Vol. 130] 
rainfall on the part of engineers occupied with water supply is considerable and fully justifies a permanent organisation of that kind; whether the same will be found in the case of thunderstorms as a result of electrical developments, wireless transmission, and aviation, remains to be seen.

The response to this enterprise has been very good for it is stated in the foreword to this report that 966 voluntary observers and organisations have contributed to it. The only criticism that suggests itself is that the working up of the statistical material does not appear to promise any notable advance in our knowledge of the conditions favourable for the development of thunderstorms, or of their life history. Great accumulations of statistical informa. tion of this kind abound in meteorology, but it only too often happens that nobody comes forward to extract new knowledge from them.
Nothing in the way of a generalisation is suggested by this report except that the regions of maximum frequency of winter thunderstorms - the western coasts of Scotland and Ireland-are roughly those of minimum frequency of summer storms. This is not new knowledge; it has been recognised with the aid of a comparatively moderate number of regular official observing stations, and the explanation is furnished by ordinary synoptic meteorology, when due attention is paid to the possible ways in which atmospheric instability can arise at the two seasons. It seems reasonable to suppose that real advance will necessitate a study of selected portions of this detailed statistical information on correspondingly detailed synoptic lines in the endeavour to trace the physical processes that accompany the development and decay of individual storms or systems of storms.

\section{Mathematical and Experimental Evidence for the Existence of a Central Intellective Factor*} By Dr. Wilutam Brown

$\mathrm{I}^{\mathrm{r}}$ a number of sufficiently dissimilar mental tests of intellective ability be applied to a group of individuals and correlation coefficients calculated, it is found that these correlation coefficients are related to one another in such a way that for any four (or tetrad) of them the following relation holds good within the limits of random sampling :

$$
r_{a p} r_{b q}-r_{a q} r_{b p}=0 \text {; }
$$

and similarly with other arrangements of these four

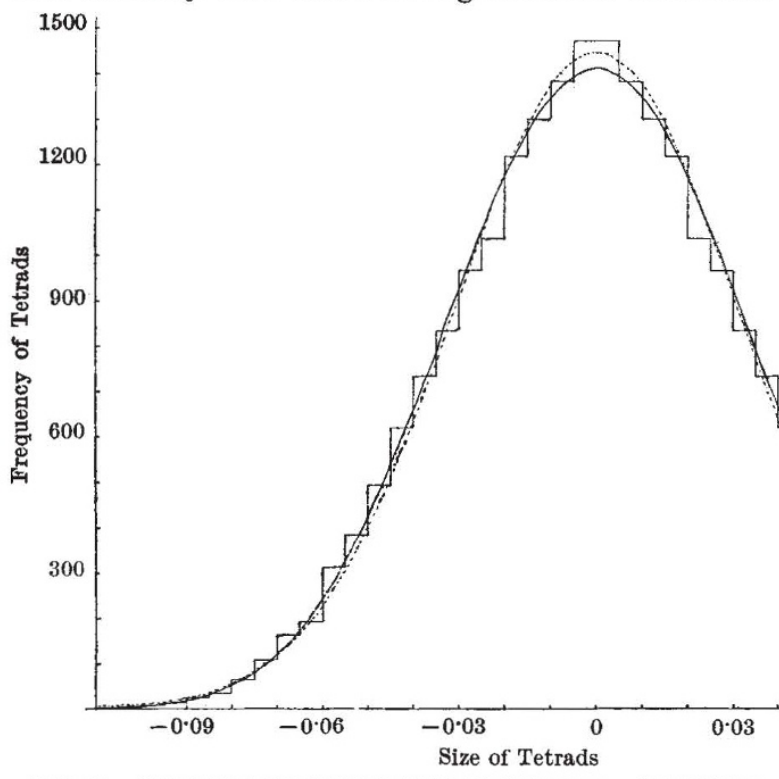

Fig. 1. Frequency distribution of tetrad differences. Best-fitting curve (Type IIa Pearson Curve) ㄴ. Best-fitting Probability Curve

coefficients. We owe both the discovery of fact and the devising of the tetrad criterion to Prof. C. Spearman.

The inference drawn from this is that the abilities measured by the mental tests are divisible into two factors each, one being common to all (the general factor, $g$ ), while the other is in each case specific and independent (the specific factor, $s$ ). ${ }^{1}$

* Summary of a paper read on Aug. 24 to the Tenth International Congress of Psychology at Copenhagen.

No. 3285, VoL. 130]
The method of applying the tetrad criterion is to draw up a frequency distribution of all the possible tetrad differences derivable from the table of correlation coefficients $\left(6 \times{ }^{n} C_{4}\right.$ in number, where $n$ is the number of mental tests correlated with one another), and to compare its standard deviation with the 'theoretical' standard deviation of a purely chance distribution of such tetrad differences. A formula for the latter has been calculated by Spearman and Holzinger.

I have re-tested my earlier correlation results of twenty to twenty-three years back $^{2}$ by this criterion, and find that, so far as they go, they do support Spearman's twofactor theory. But a statistically adequate proof of the theory needs a large random sample of cases (several hundreds) and, especially, a large number of not too similar mental tests of intellectual ability -much larger than those applied in any research up to the present date. ${ }^{3}$

To fulfil these conditions, I have organised a research during the past year with the help of Prof. Spearman and Dr. W. Stephenson of University College, London. Dr. Stephenson has devised a series of twenty tests of apparently non-overlapping intellective ability, selected not a priori but after much preliminary trial, which received the approval of Prof. Spearman, and has applied them for me to 300 boys, aged 101-11 years, drawn from twelve elementary schools of the L.C.C., forming a homogeneous random 'sample' of adequate size for statistical purposes. The total number of positive tetrad differences is 14,535 (and there is an equal number of negative tetrad differences, of course). It has since been found necessary to reject one of the tests and one of the correlation coefficients. There remain 11,356 